\title{
Editorial
}

Digestion

\section{Prognostic Markers in Gastrointestinal Stromal Tumors - We Are Not There Yet}

\author{
Rafael Bruck ${ }^{a}$ Nadir Arber ${ }^{b}$ \\ a Institute of Gastroenterology and Liver Diseases, and the ${ }^{\mathrm{b}}$ Integrated Cancer Prevention, Tel Aviv Sourasky \\ Medical Center and the Sackler School of Medicine, Tel Aviv University, Tel Aviv, Israel
}

Gastrointestinal stromal tumors (GISTs) comprise the largest subset of mesenchymal tumors of the digestive tract. It has been suggested that these tumors originate from the interstitial cells of Cajal or from their stem celllike precursors [1]. Most GISTs have an activating mutation in the $c$-kit protooncogene that leads to constitutive expression of Kit protein, a tyrosine kinase specific to the stem cell factor [2]. Therefore, in the context of appropriate morphology, these tumors are best defined by Kit (CD-117)-positive immunostaining. Recently, an activating mutation of platelet-derived growth factor receptor- $\alpha$ (PDGFR $\alpha$ ) was identified to comprise $\sim 5 \%$ of GISTs [3, 4]. GISTs have a wide range of biological behaviors, including benign, borderline and malignant variants. Approximately $20-25 \%$ of gastric and $40-50 \%$ of small intestinal GISTs are clinically malignant [5]. The treatment of GIST is complete excision when possible, and treatment with Kit/PDGFR $\alpha$ tyrosine kinase inhibitors, such as imatinib, when the tumor is unresectable or in the metastatic setting. The majority of patients can achieve complete or partial remission. Long-term success is limited by the development of imatinib resistance, usually based on secondary mutations in the Kit or PDGFR $\alpha$ tyrosine kinase domains $[6,7]$.

The most widely examined criteria for evaluating biologic potential of GISTs are tumor size and mitotic activity $[8,9]$. Unfortunately, these indices do not guarantee a benign clinical course, as small GISTs with a low mitotic index have been known to metastasize. This has prompted the development of guidelines for defining risk of aggressive behavior rather than classifying lesions as either benign or malignant [10]. These guidelines, which were developed during a NIH consensus conference in 2001, are based on the idea that all GISTs have some potential for aggressive clinical behavior. Other pathological features of GISTs, in addition to mitotic index and tumor size, such as cellularity, mucosal invasion and ulceration, were also evaluated for prognostic significance, but have not gained wide acceptance [11]. Kit mutation status has also been evaluated in terms of prognosis. However, since approximately $90 \%$ of GISTs contain either Kit or PDGFR $\alpha$ mutations, the presence or absence of a mutation does not, by itself, distinguish between benign and malignant GISTs $[12,13]$. Preliminary studies indicate that accumulation of secondary cytogenetic abnormalities/ molecular alterations [12], Ki-67 proliferative index and telomerase activity are associated with clinically aggressive behavior [14]. Aberration of the cell cycle regulators is a frequent finding and may be a contributing factor in the pathogenesis of GIST. Indeed, malignant GISTs are more likely to be associated with a positive $\mathrm{E} 2 \mathrm{~F} 1$ and p53 phenotype and a negative p16 and p2 $7^{\text {kipl }}$ phenotype [1517]. For p2 $7^{\text {kip1 }}$, a member of the Cip/Kip family, a tumor suppressor role was demonstrated in mice, and a decrease or loss of the p2 $7^{\mathrm{kip} 1}$ protein was found to be a predictor of poor prognosis in many human cancers, including gas-

\section{KARGER}

Fax +4161306 1234 E-Mail karger@karger.ch www.karger.com (c) 2007 S. Karger AG, Basel

0012-2823/07/0751-0001\$23.50/0

Accessible online at:

www.karger.com/dig
Rafael Bruck, MD

Department of Gastroenterology and Liver Diseases

Tel Aviv Sourasky Medical Center

6 Weizman Street, Tel Aviv 64239 (Israel)

E-Mail rafib@tasmc.health.gov.il 
trointestinal malignancies $[18,19]$. An inverse correlation was demonstrated for different tumors between p27 expression and tumor grade, stage and survival [20]. Several studies demonstrated a negative correlation between p27 and Ki-67 proliferation index supporting the role of p27 as a prognostic marker GISTs [16, 21, 22], on the other hand a more recent study could not confirm these finding [23].

In this issue of Digestion, Shirin et al. [24] examined in 36 patients with surgically resected GISTs, whether p27 may predict the malignant potential of the tumor. The patients were classified into benign or malignant GISTs. Clinically, 25 patients $(\sim 70 \%)$ had benign GIST with no involvement of regional lymph nodes or distant metastases. Using immunohistochemistry, tumor specimens were stained for p27 and the proliferation marker, Ki-67. The authors observed a significant difference between low- and high-risk GIST groups for Ki-67 expression, while no difference was identified for p27 expression, tumor size or predominant cell type (i.e., spindle or epithelioid). Ten patients died due to causes unrelated to their GISTs: 5 died perioperatively and another 5 patients died during follow-up from other causes. Only 1 patient died because of recurrent GIST. With only one GIST-related death (an exceptionally favorable prognosis for GIST patients with a 10-year follow-up), it is not possible to conclude, from this study, any correlation between p27 expression and survival. Therefore, this study does not clearly exclude an association between p27 expression and patients' prognosis, but rules out a correlation with the stage of the tumor during surgery.

Although in this study the percentage of patients with low-risk GISTs is small (i.e., 16\%), which may hamper the recognition of statistically significant differences in the expression of $\mathrm{p} 27$ between the two groups, a significant difference could be seen in the Ki-67 expression between the low- and high-risk groups. Unexpectedly, in this study, a trend for higher p27 expression was found in the more advanced tumors (although not statistically significant), in contrast to previous studies where low p27 expression was associated with an unfavorable prognosis $[16,20-22]$.

In summary, this study suggests that p27 expression cannot serve as a predictor for the aggressiveness of GIST, and therefore cannot predict prognosis or indications for further treatment after surgery. It should be emphasized, however, that since there was only 1 case that died as a result of his GIST, p27 expression cannot be used as a prognostic marker. Clearly, more research is necessary to elucidate new markers with a good correlation to prognosis that will aid in selecting those patients who will require additional therapy following surgical resection.

\section{References}

1 Rubin BP, Fletcher JA, Fletcher CD: Molecular insights into the histogenesis and pathogenesis of gastrointestinal stromal tumors. Int J Surg Pathol 2000;8:5-10.

2 Hirota S, Isozaki K, Moriyama Y, et al: Gainof-function mutations of c-kit in human gastrointestinal stromal tumors. Science 1998; 279:577-580.

3 Heinrich MC, Corless CL, Duensing A, et al: PDGFR $\alpha$ activating mutations in gastrointestinal stromal tumors. Science 2003;299: 708-710.

4 Hirota S, Ohashi A, Nishida T, et al: Gain-offunction mutations of platelet-derived growth factor receptor- $\alpha$ gene in gastrointestinal stromal tumors. Gastroenterology 2003;125:660-667.

5 Miettinen M, Lasota J: Gastrointestinal stromal tumors. Review on morphology, molecular pathology, prognosis, and differential diagnosis. Arch Pathol Lab Med 2006;130: 1466-1478.
6 Tamborini E, Bonadiman L, Greco L, et al: A new mutation in the KIT ATP pocket causes acquired resistance to imatinib in a gastrointestinal stromal tumor patient. Gastroenterology 2004;127:294-299.

7 Chen LL, Sabripour M, Andtbacka RH, et al: Imatinib resistance in gastrointestinal stromal tumors. Curr Oncol Rep 2005;7:293299.

8 Miettinen M, Sobin LH, Lasota J: Gastrointestinal stromal tumors of the stomach: a clinicopathologic, immunohistochemical, and molecular genetics studies of 1,765 cases with long-term follow-up. Am J Surg Pathol 2005;29:52-68.

9 Miettinen M, Makhlouf HR, Sobin LH, Lasota J: Gastrointestinal stromal tumors of the jejunum and ileum: a clinicopathologic, immunohistochemical, and molecular genetics studies of 906 cases prior to imatinib with long-term follow-up. Am J Surg Pathol 2006;30:477-489.

10 Fletcher CD, Berman JJ, Corless C, et al: Diagnosis of gastrointestinal stromal tumors: a consensus approach. Hum Pathol 2002;33: 459-465.
11 Rubin BP: Gastrointestinal stromal tumours: an update. Histopathology 2006;48:83-96.

12 Heinrich MC, Rubin BP, Longley BJ, et al: Biology and genetic aspects of gastrointestinal stromal tumors: KIT activation and cytogenetic alterations. Hum Pathol 2002;33:484495.

13 Rubin BP, Singer T, Tsao C, et al: KIT activation is a ubiquitous feature of gastrointestinal stromal tumors. Cancer Res 2001;61: 8118-8121.

14 Kawai J, Kodera Y, Fujiwara M, et al: Telomerase activity as prognostic factor in gastrointestinal stromal tumors of the stomach. Hepatogastroenterology 2005;52:959-964.

15 Sabah M, Cummins R, Leader M, et al: Loss of heterozygosity $9 \mathrm{p}$ and loss of p16(INK4A) expression are associated with malignant gastrointestinal stromal tumors. Mod Pathol 2004;17:1364-1371.

16 Schneider-Stock R, Boltze C, Lasota J, et al: Loss of p16 protein defines high-risk patients with gastrointestinal stromal tumors: a tissue microarray study. Clin Cancer Res 2005; 11:638-645. 
17 Sabah M, Cummins R, Leader M, et al: Altered expression of cell cycle regulatory proteins in gastrointestinal stromal tumors: markers with potential prognostic implications. Hum Pathol 2006;37:648-655.

18 Mori M, Mimori K, Shiraishi T, et al: p27 expression and gastric carcinoma. Nat Med 1997;3:259-264.

19 Singh SP, Lipman J, Goldman H, et al: Loss of altered subcellular localization of p27 in Barrett's associated adenocarcinoma. Cancer Res 1998;58:1730-1735.20
Lloyd RV, Erickson LA, Jin L, et al: $\mathrm{p}^{27 k i p 1}$ : a multifunctional cyclin-dependent kinase inhibitor with prognostic significance in human cancers. Am J Pathol 1999;154:313323.

21 Pruneri G, Mazzarol G, Fabris S, et al: Cyclin D3 immunoreactivity in gastrointestinal stromal tumors is dependent of cyclin D3 gene amplification and is associated with nuclear p27 accumulation. Mod Pathol 2003 886-892.
22 Gelen TG, Elpek GO, Aksoy NH, et al: p27 labeling index and proliferating gastrointestinal stromal tumors: correlations with clinicopathologic factors and recurrence. Jap J Clin Oncol 2003;33:346-352.

23 Nakamura N, Yamamoto $\mathrm{H}$, Yao $\mathrm{T}$, et al: Prognostic significance of expressions of cell-cycle regulatory proteins in gastrointestinal stromal tumor and the relevance of the risk grade. Hum Pathol 2005;36:828-837.

24 Shirin H, Kravtsov V, Shahmurov M, Sehayek Shabat V, Krinshpon I, Alin A, Avinoach I, Avni Y: The cyclin-dependent kinase inhibitor, P27 $7^{\mathrm{kip} 1}$, has no correlation with the malignant potential of GIST. Digestion 2007;75:4-9. 